\title{
PENGARUH NAUNGAN TERHADAP PERTUMBUHAN DAN LAJU FOTOSINTESIS TANAMAN CABE MERAH (Capsicum annuum L) SEBAGAI SALAH SATU SUMBER BELAJAR BIOLOGI
}

\author{
Mustofa Khoiri \\ Guru MAN 2 Metro dan Dosen Pendidikan Biologi FKIP \\ Universitas Muhammadiyah Metro, E-mail: mustofahel@yahoo.com
}

\begin{abstract}
Abstrak: This research aim to know the effect of wings of to growth and photosynthesis speed at red pepper crop. The result of the research indicates that wings of to red pepper crop from aspect morfologis haves an in with plant height and plane flattened dry weight, but at leaf wide, leaves, and effect leaf length wings of doesn't significan influence compared with control. From physiological aspect, wings of at red pepper crop influences value quantum yield, photochemical quenching, and non photochemical quenching, but at value Q max doesn't show real influence. In aspect ecophyisiologic, wings of triggering produce of prolin and ascorbic acid which significan. Inferential that red pepper Capsicum annuum $L$ very responsive in process of adaptation to environmental change for example grasp in the form of low light intensity. The result of the research gives contribution as source of teaching material in biology learning.
\end{abstract}

Kata kunci: Naungan, Capsicum апnиит L, aspek ekofisiologis.

Cabe merah (Capsicum annuum $\mathrm{L}$ ) termasuk ke dalam famili Solanaceae. Terdapat sekitar 20 - 30 spesies yang termasuk ke dalam genus Capsicum diantaranya adalah lima spesies yang telah dibudidayakan yaitu Capsicum baccatum, Capsicum pubescens, Capsicum annuum, Capsicum chinense, Capsicum frutescent. Tanaman cabe dapat tumbuh pada berbagai jenis tanah. Tanah yang paling ideal untuk tanaman cabai adalah yang mengandung bahan organic sekurang kurangnya $1.5 \%$ dan mempunyai $\mathrm{pH}$ antara 6.0-6.5. Keadaan $\mathrm{pH}$ tanah sangat penting karena erat kaitannya dengan ketersediaan unsur hara Apabila ditanam di tanah dengan $\mathrm{pH}$ lebih dari 7 tanaman cabe akan menunjukkan gejala klorosis, yakni tanaman akan kerdil dan daun akan menguning yang disebabkan oleh kekurangan unsur hara besi (Fe). Sebaliknya apabila $\mathrm{pH}$ kurang dari lima tanaman juga akan kerdil karena kekurangan unsure calsium (Ca) dan Magnesium $(\mathrm{Mg})$ atau keracunan aluminium atau mangan (Sumarni, 1996).

Pertumbuhan akan optimal apabila semua komponen tersedia dalam jumlah yang seharusnya. Suhu ,ketersediaan $\mathrm{CO} 2$, dan cahaya merupakan unsur dalam kegiatan fotosintesis. Pada umumnya tumbuhan daerah tropis tidak mampu melakukan fotosintesis pada suhu $5^{\circ} \mathrm{C}$, maka meskipun sinar ada, $\mathrm{CO}_{2}$ terpenuhi kegiatan fotosintesis akan terhambat dalam hal ini dapat dikatakan bahwa temperatur merupakan faktor penghambat (limiting factor). Demikian pula $\mathrm{CO}_{2}$ terpenuhi, suhu optimum (antara $10-35{ }^{\circ} \mathrm{C}$ ) tetapi sinar kurang 
banyak maka fotosintesis juga akan menjadi terhambat, hal ini dikatakan bahwa sinar juga menjadi faktor penghambat proses fotosintesis (Dwijoseputro, 1990). Faktor cahaya, suhu, $\mathrm{CO}_{2}$,air dan zat hara mempengaruhi laju fotosintesis tanaman (Treshow, 1970) dan berpengaruh pada kepadatan kanopi ,ukuran dan bentuk daun serta sudut letak daun (Hughes, 1965). Apabila lingkungan subur, air tersedia dan suhu yang sesuai ,maka radiasi merupakan faktor utama yang mempengaruhi pertumbuhan dan hasil tanaman (Fisher, 1975) dan terdapat hubungan yang erat antara radiasi dengan fotosintesis bersih (Wilson, 1980).

Terdapat perbedaan morfologi daun yang berhubungan dengan proses fotosintesis: ketebalan daun, kloroplas, anatomi daun, dan enzim siklus Calvin. perubahan ini di respon tumbuhan dengan laju fotosintesis turun, berfotosintesis dengan laju tinggi walaupun dengan cahaya rendah, titik kompensasi cahayanya sangat rendah sehingga pertumbuhannya sangat lambat (Salisbury dan Rose, 1991).

Sel tumbuhan tertentu yang yang terpapar kondisi lingkungan yang kurang cocok misalnya kekeringan, kadar garam, temperatur rendah, dan naungan akan menghasilkan prolin untuk menjaga keseimbangan osmotik sel. Hal ini dilakukan untuk mengatur tekanan osmotik pada kondisi cekaman (osmotic adjustment). Gen yang menyandi proline dehydrogenase yang adalah bertanggung jawab untuk oksidasi proline sebagai regulator terhadap cekaman (Leegood, 2001).

Asam askorbat memenuhi banyak fungsi penting pada biologi tanaman Asam askorbat juga digunakan sebagai ko-faktor untuk violaxantin deoxidase pada siklus xanthopyl. Proses ini dilibatkan dalam perlindungan pelepasan penyerapan cahaya dalam bentuk panas dan bisa diukur sebagai nonfhotochemical quenching dari fluorosence klorofi. Fungsi biologis ascorbic peroksidase (APX) adalah mencegah akumulasi $\mathrm{H}_{2} \mathrm{O}_{2}$ dan enzim mengkatalisasi suatu reaksi di mana askorbat bertindak sebagai donor elektron dan $\mathrm{H}_{2} \mathrm{O}_{2}$ mengalami reduksi menjadi air (Ayhan, 2000).

Laju fotosintesis tanaman salah satunya bisa diukur dari fluorescence klorofil yang terjadi pada awal periode fotosintesis. Tiap quantum cahaya yang diserap oleh molekul klorofil akan meningkatkan elektron dari kondisi ground state ke excited state. Secara umum, fluorescence yield tinggi ketika reaksi fotokimia dan pelepasan dalam bentuk bahang rendah. Oleh karena itu perubahan fluorescence yield mencerminkan perubahan efisiensi fotokimia dan perubahan pelepasan dalam bentuk bahang.

\section{METODE}

Penelitian ini dilaksanakan di green hause selama 21 hari dengan menggunakan tanaman cabe merah (Capsicum annuum, L) yang ditanam di polibag dengan media tanam tanah dan kompos $2: 1$, dengan rancangan acak lengkap dan 5 kali ulangan. Data morfologi diperoleh dari pengamatan jumlah daun, lebar daun, panjang daun, dan tinggi batang. Data ini diambil pada saat menjelang perlakuan dan dianggap sebagai data T0. Setelah hari ke 8 dalam perlakuan dilakukan kembali pengambilan data morfologis. Pada pengukuran akhir aspek morfologi tidak selengkap seperti pada data awal (T0), hal ini disebabkan pada pengukuran jumlah laju fotosintesis menggunakan daun sebagai bahan uji. Pada akhir sebelum penyimpanan dilakukan 
penimbangan pada bobot kering akar dan tajuk.

\section{Analisis Prolin}

Analisis prolin dilakukan dengan menggunakan spectrophotometer: Sebanyak $0.5 \mathrm{~g}$ sample daun digerus dengan $10 \mathrm{ml}$ asam sulfosalisilik 3\% kemudian hasil gerusan disaring dengan filtrat Wathman no 42. Sebanyak $2 \mathrm{ml}$ filtrate direaksikan dengan $2 \mathrm{ml}$ asam ninhydrin (mengandung $1.25 \mathrm{~g}$ ninyhidrin dihangatkan (suhu $60^{\circ} \mathrm{C}$ ) dalam $2 \mathrm{ml}$ asam asetat glacial di dalam tabung reaksi. Larutan tersebut di oven $100{ }^{\circ} \mathrm{C}$ selama 1 jam.kemudian larutan didinginkan segera dalam ice bath sampai beberapa menit ( dingin ). Tambahkan $4 \mathrm{ml}$ toluene ke dalam tabung reaksi, vortek sekitar 15 sampai 20 detik sampai terlihat adanya pemisahan larutan ,ambil larutan yang bagian atas (terlihat agak merah muda) masukkan ke dalam tabung spectrophotometer. Hasil pemisahan larutan tersebut dispectro pada panjang gelombang $520 \mathrm{~nm}$, dan sebagai blangkonya dipakai toluene. Standar prolin diperlukan untuk mengetahui prolin murni pada berbagai konsentrasi prolin dengan menggunakan kurva standar prolin. Sample diganti dengan prolin murni yang dilarutkan dalam asam sulfosalisilik $3 \%$ dengan konsentrasi 20 , $10,5,2.5,1.25,0.625$ ppm.

Konsentrasi prolin ditentukan dari kurva standar dan dihitung berdasarkan berat segar yaitu: ( $\mu \mathrm{g}$ prolin $/ \mathrm{ml}$ toluene) / $115.5 \mu \mathrm{g} / \mu \mathrm{mol}$ (g sample) / $5=\mu \mathrm{mol}$ prolin / $\mathrm{g}$ bobot basah bahan.

\section{Analisis Asam askorbat}

Metode yang dipakai adalah metode titrasi asidialkali, berdasarkan perubahan asam menjadi basa dengan langkah langkah sebagai berikut: Sampel daun ( $5 \mathrm{gr}$ ) digerus dalam $10 \mathrm{ml}$ asam metafosforik 5\%. Hasil gerusan disaring dengan filter Wathman no1. Filtrat yang diperoleh ditritasi dengan dichlorofhenol-indophenol (DCIP) $0.8 \mathrm{gr}$ $1^{-1}$. Titrasi dihentikan ketika filtrate tepat berwarna pink. Standar asam askorbat diketahui dengan mentritasi asam askorbat murni yaitu $1 \mathrm{ml}$ larutan yang mengandung asam askorbat (4.0 $\mathrm{mg} \mathrm{l}^{-1}$ ) dan $9 \mathrm{ml}$ asam metaphosphorik $5 \%$ ditritasi dengan dichlorophenolindophenol ( DCIP) $0.8 \mathrm{~g} \mathrm{l}^{-1}$

Kandungan ASA diperoleh dengan rumus sebagai berikut:

a. Untuk standarisasi larutan ASA ( 4 mg ASA murni equivalent dengan $1 \mathrm{ml}$

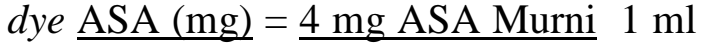
dye yang ditritasi $(\mathrm{ml})$

b.Untuk mengetahui kandungan ASA daun tanaman (ASA $100 \mathrm{~g}^{-1}$ jaringan daun): $m g$ ASA per aliquot $x$ [total volume ekstrak (ml) /volume aliquot (ml)]x [100/berat sample]

\section{Pengukuran laju fotosíntesis}

Pengukuran laju fotosintesis diukur dengan menggunakan perangkat quibet system. Daun tanaman diletakkan pada "kuvet". Daun diututup dengan kain hitam selama lebih kurang 20 menit. Saturating flash dinyalakan, fluorescence akan meningkat dari nilai ground state (Fo) ke nilai maksimum $(\mathrm{Fm})$. Dari sini diperoleh efisiensi quantum maksimum dengan rumus: $\mathrm{Fv} / \mathrm{Fm}=(\mathrm{Fm}-\mathrm{Fo}) / \mathrm{Fm}$. Actinic light dinyalakan, pada kondisi ini fluorescence yield meningkat yaitu pada kondisi nilai steady state (Ft). Saturating flash dinyalakan interval 20 detik, akan meningkatkan fluorescence yield pada kondisi maksimum (Fm') (nilainya akan lebih rendah dari kondisi gelap (tanpa actinic light on). Maka diperoleh photochemical quenching $(\mathrm{qP})=(\mathrm{Fm}$ '- 
$\mathrm{Ft}) /(\mathrm{Fm}$ '-Fo), non photochemical quenching $(\mathrm{NPQ})=\left(\mathrm{Fm}-\mathrm{Fm}{ }^{\prime}\right) / \mathrm{Fm}$ ' dan quantum yield dari transfer elektron pada PSII $(\Phi P S I I)=\left(F m^{\prime}-F t\right) / F m$ ' dan yang terakhir diperoleh Fv'/Fm'[(Fm'Fo')/Fm'].

\section{HASIL}

Data morfologis yang diambil dalam penelitian ini adalah tinggi

Tabel 1. Nilai rata rata pengaruh naungan terhadap panjang akar,tajuk, serta berat kering akar dan tajuk

\begin{tabular}{|l|l|l|}
\hline \multicolumn{1}{|c|}{ Parameter } & Kontrol & Naungan \\
\hline Panjang akar & $19.80 \mathrm{~cm}$ & $18.10 \mathrm{~cm}$ \\
Panjang Tajuk & $13.88 \mathrm{~cm}$ & $12.18 \mathrm{~cm}$ \\
Berat Kering Akar & $0.209 \mathrm{gr}$ & $0.102 \mathrm{gr}$ \\
Berat Kering & $0.119 \mathrm{gr}$ & $0.062 \mathrm{gr}$ \\
Tajuk & & \\
\hline
\end{tabular}

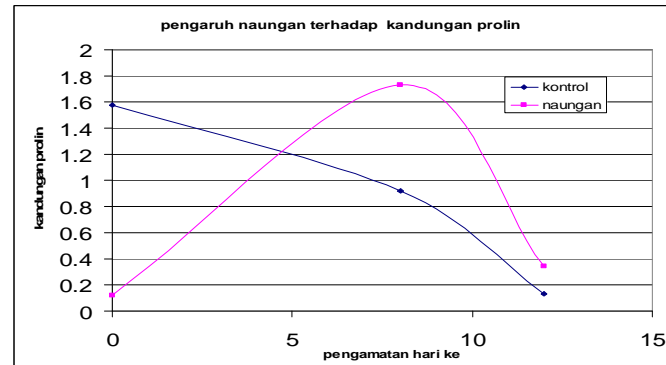

Gambar 1.Pengaruh naungan terhadap prolin

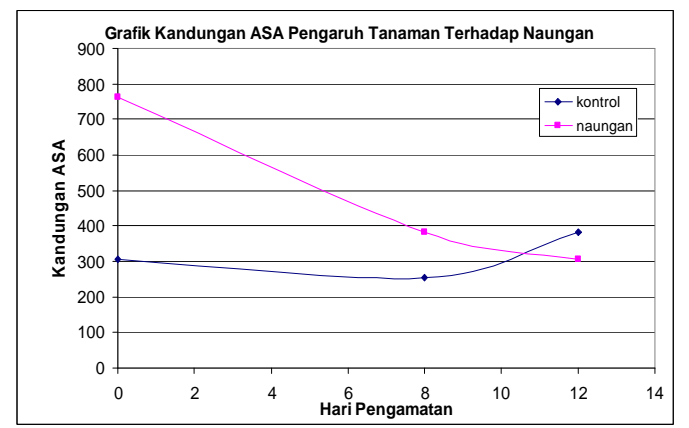

Gambar 2. Pengaruh naungan terhadap asam askorbat tanaman, banyak daun, dan panjang daun. Hasil pengamatan menunjukkan rata-rata ada perbedaan peningkatan tinggi tanaman. Pada control, peningkatan rata rata tinggi tanaman sekitar $1 \mathrm{~cm}$ yaitu dari $4.7 \mathrm{~cm}$ menjadi $5.7 \mathrm{~cm}$. Sedangkan pada perlakuan naungan peningkatan tinggi tanaman lebih besar yaitu $3.1 \mathrm{~cm}$ dari $2 \mathrm{~cm}$ menjadi $5,1 \mathrm{~cm}$.
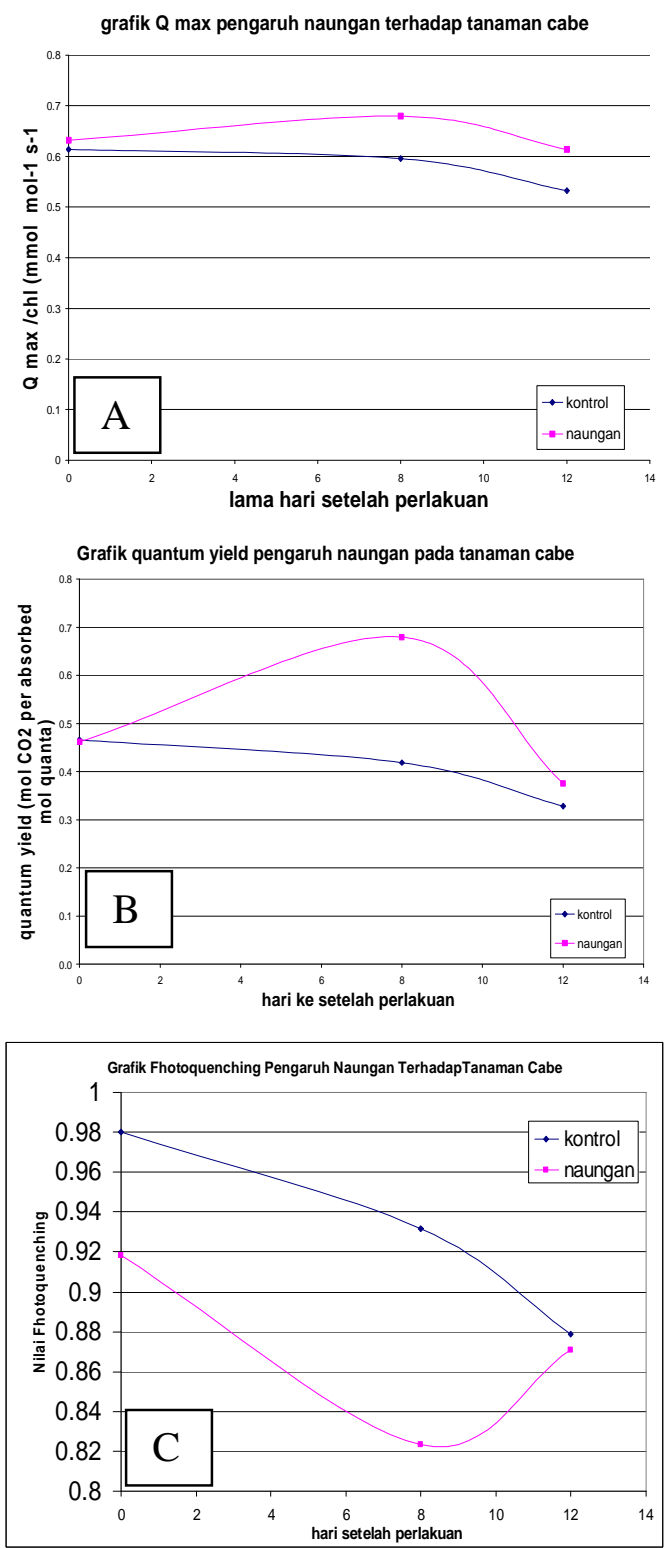


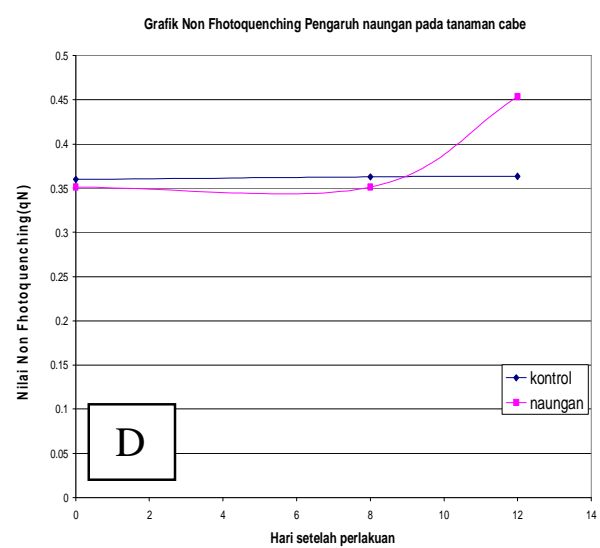

PEMBAHASAN

Tanaman cabe yang dinaungi memiliki rata rata peningkatan tinggi tanaman lebih tinggi dibandingkan dengan tanaman cabe yang tidak dinaungi . Hal ini sesuai dengan hasil penelitian Darmijati (1992) pada tanaman kedelai varietas orba tinggi tanaman pada perlakuan naungan lebih tinggi dari pada tanaman tanpa naungan. Adaptasi tanaman terhadap naungan akan mempengaruhi morfologi , anatomi, dan fisiologi tanaman, diantaranya dapat melalui peningkatan luas daun dan tinggi tanaman sebagai upaya mengurangi penggunaan metabolit, dan mengurangi cahaya yang ditransmisikan dan direfleksikan (Hale dan Oreutt, 1970)

Pada pengamatan banyaknya daun, naungan mempengaruhi terbentuknya daun pada kelompok perlakuan. Pada tanaman cabe naungan mempunyai rata-rata jumlah daun yang lebih tinggi dari tanaman cabe kontrol. Hal ini berkaitan dengan adanya usaha untuk meningatkan laju fotosintesis. Tumbuhan pada naungan akan meningkatkan laju fotosintesis diantaranya dengan memperbanyak jumlah kloroplas (Lambers, 1998).

Untuk pengamatan panjang akar, panjang tajuk serta berat kering akar dan berat kering tajuk dapat dilihat dalam tabel berikut :

Dari data panjang dan berat kering antara akar dan tajuk, perlakuan naungan memiliki nilai rata rata panjang dan berat kering lebih rendah dibandingkan dengan kontrol, naungan menyebabkan titik kompensasi cahaya sangat rendah dan menyebabkan pertumbuhannya sangat lambat (Salisbury dan Rose, 1991). Produksi biomassa mengakibatkan bobot, dapat diikuti dengan pertambahan lain yang dapat dinyatakan secara kuantitatif. Oleh karena itu pengukuran biomassa total tanaman akan merupakan parameter yang paling baik digunakan sebagai indikator pertumbuhan tanaman. Bahan kering tanaman dipandang sebagai manisfestasi dari semua proses dan peristiwa yang terjadi dalam pertumbuhan tanaman. Karena itu variabel ini dapat digunakan sebagai ukuran global pertumbuhan tanaman dengan segala peristiwa yang dialaminya (Sitompul dan Guritno, 1995).

\section{Analisis Prolin}

Sel tumbuhan yang terpapar kondisi lingkungan yang kurang cocok misalnya kekeringan, kadar garam, temperatur rendah, dan naungan akan menghasilkan prolin untuk menjaga keseimbangan osmotik sel. Mengatur tekanan osmotik pada kondisi cekaman atau dikenal dengan osmotic adjustment akan menghasilkan senyawa terlarut yang diakumulasi selama proses osmotic adjustment seperti senyawa gula dan asam prolin. Kandungan prolin tanaman cabe pada perlakuan kontrol mengalami penurunan sampai pengamatan terakhir. Sedangkan pada perlakuan naungan kandungan prolin mengalami peningkatan yang tajam dari pada pengamatan hari ke 8, kemudian mengalami penurunan sampai 
pengamatan terakhir (Gambar 1). Peningkatan kandungan prolin adalah mekanisme osmotic adjustment terhadap intensitas cahaya kurang akibat perlakuan naungan. Pada akhir pengamatan kandungan prolin untuk kedua perlakuan mendekati angka yang sama, karena tanaman cabe pada perlakuan naungan sudah mengalami proses adaptasi terhadap intensitas cahaya rendah.

\section{Analisis Asam Askorbat}

Asam askorbat merupakan asam organik dengan kemampuan antioksidan yang mudah larut dalam air dan sangat mudah dioksidasi sebagai senyawa reduktan. Asam askorbat akan rusak bila ditempatkan pada cahaya atau panas yang akan berubah dalam bentuk teroksidasi yaitu asam dehidroaskorbat (Anonym, 2007). Fungsi biologis askorbat peroksidase (APX) adalah mencegah akumulasi $\mathrm{H}_{2} \mathrm{O}_{2}$ dan, enzim mengkatalisasi suatu reaksi di mana ascorbat bertindak sebagai donor elektron dan $\mathrm{H}_{2} \mathrm{O}_{2}$ mengalami reduksi menjadi air (Ayhan, 2000).

Hasil pengamatan menunjukkan tanaman kontrol mengalami penurunan di awal dan mengalami peningkatan pada hari ke 8 sampai pengamatan terakhir (Gambar 2). Sedangkan pada perlakuan naungan kandungannya terus mengalami penurunan dari awal pengamatan sampai hari terakhir. Hal ini sesuai dengan fungsi asam askorbat bagi tumbuhan sebagai ko-faktor untuk violaxantin deoxidase pada siklus xanthopyl. Proses ini berperan dalam perlindungan pelepasan penyerapan cahaya dalam bentuk panas dan bisa diukur sebagai nonfhotochemical quenching dari fluorosence klorofil. Asam askorbat sebagai senyawa antioksidan dapat berinteraksi dengan membran plasma dan mendonorkan elektronnya ke radikal $x$-tocopheroxyl dan aktifitas-trans-membran plasma oksidoreduktase. Recycling $x$ tocopheroxyl dapat membantu melindungi membran plasma dari peroksidasi (Anonym, 2007).

\section{Laju Fotosintesis}

$\begin{array}{rrrr}\text { fengan } & \text { optosintesis } & \text { dapat } & \text { berjalan } \\ \text { apabila } & \text { semua }\end{array}$ komponen tersedia dalam jumlah yang seharusnya. Suhu, ketersediaan $\mathrm{CO}_{2}$, cahaya merupakan unsur yang berperan dalam kegiatan fotosintesis. Maka untuk mengetahui laju fotosintesis dapat dilihat dari nilai $\mathrm{Q}$ mak (quantum maksimal), photochemical quenching (PQ), dan non photochemical quenching (NPQ).

Dari grafik $A$ diperoleh nilai $Q$ max pada perlakuan naungan terjadi peningkatan dari hari ke 0 sampai hari ke 8 , setelah itu menunjukkan penurunan sampai pengamatan terakhir hari ke 12 . Sedangkan pada perlakuan kontrol terjadi penurunan dari hari ke 0 sampai hari ke 12. Naungan secara langsung berpengaruh terhadap intensitas cahaya yang sampai dipermukaan tajuk tanaman. Dari grafik B diperoleh nilai Quantum yield pada perlakuan naungan terjadi peningkatan dari hari ke 0 sampai hari ke 8, setelah itu menunjukkan penurunan sampai pengamatan terakhir hari ke 12. Sedangkan pada perlakuan kontrol terjadi penurunan dari hari ke 0 sampai hari ke 12. Naungan secara langsung berpengaruh terhadap intensitas cahaya yang sampai dipermukaan tajuk tanaman. .Pemberian naungan pada tnaman selain mengurangi intensitas cahaya juga spektrum cahaya yang diterima daun dibawah naungan akan berbeda dengan spectrum cahaya langsung (Edmond et al, 1983).

Dari grafik $\mathrm{C}$ nilai photochemical quenching untuk perlakuan kontrol 
terjadi penurunan dari hari ke 0 sampai pengamatan terakhir hari ke 12, sedangkan pada perlakuan naungan terjadi penurunan $\mathrm{qP}$ pada pengamatan dari hari ke 0 sampai hari ke 8, selanjutnya nilai qP mengalami peningkatan sampai pengamatan hari ke 12, hal ini berarti mulai terjadi aklimasi terhadap perubahan cahaya rendah. Pada akhirnya nilai $\mathrm{qP}$ antara pada pengamatan terakhir antar perlakuan kontrol dan naungan mendekati nilai yang sama

Dari grafik D nilai NPQ untuk perlakuan kontrol dan naungan pada pengamatan hari ke 0 sampai hari ke 8 tidak mengalami perubahan. Pada perlakuan naungan setelah hari ke 8 mengalami peningkatan yang nyata, sedangkan pada perlakuan kontrol tidak mengalami perubahan sampai pada pengamatan hari terakhir.

Sebagai salah satu sumber belajar biologi, kajian ini mendukung materi pokok pertumbuhan dan perkembangan. Guru biologi dapat memanfaatkan metode maungan dalam kegiatan eksperimen bagi siswa. Perangkat pendukung yang dibutuhkan adalah petunjuk praktikum dan lokasi kegiatan praktikum (green house atau kebun sekolah). Pemanfaatan hasil penelitian ini secara langsung, sebagai suplemen materi pokok pertumbuhan dan perkembangan dengan memasukkannya sebagai informasi pengayaan materi pembelajaran biologi.

\section{KESIMPULAN DAN SARAN}

\section{Kesimpulan}

Berdasarkan hasil dan pembahasan dapat disimpulkan bahwa pemberian naungan pada tanaman cabe merah Capsicum annuum $L$ dari aspek morfologis berpengaruh pada tinggi tanaman dan rata rata berat kering secara nyata, tetapi pada lebar daun, banyak daun, dan panjang daun pengaruh naungan tidak mempengaruhi secara signifikan dibandigkan dengan kontrol. Dari tinjauan laju fotosintesis naungan pada tanaman cabe mempengaruhi pada nilai quantum yield, photochemical quenching, dan non photochemical quenching tetapi pada nilai Q mak tidak memperlihatkan pengaruh yang tidak nyata. Tanaman cabe adalah tanaman yang relatif lebih rentan terkena dampak dari naungan. Dari tinjauan aspek ekofisiologis perlakuan pemberian naungan telah memicu produksi prolin dan asam askorbat yang cukup signifikan. Tanaman cabe merah Capsicum annuum $L$ sangat responsif dalam proses adaptasi terhadap perubahan lingkungan misalnya cekaman berupa intensitas cahaya yang rendah.

\section{Saran}

Dalam rangka meningkatkan hasil dari budidaya tanaman cabe maka perlu diperhatikan bahwa untuk mendapatkan hasil optimal maka harus diperhatikan beberapa faktor. Selain memenuhi unsur hara tanah, maka harus diupayakan agar proses fotosintesis sebagai proses utama dalam menghasilkan buah cabe yang berkualitas harus diusahakn seoptimal mungkin dengan cara menghindarkan dari naungan yang berlebihan.

Sebagai sumber belajar biologi, kajian ini mendukung materi pokok pertumbuhan dan perkembangan. Kepada guru biologi disarankan untuk mengembangkan perangkat pembelajaran dengan memasukkan informasi hasil penelitian ini, sehingga memperkaya pengetahuan siswa tentang pertumbuhan dan perkembangan. Selain itu, langkah-langkah metode penelitian ini dapat dilaksanakan dalam kegiatan eksperimen. 


\section{DAFTAR RUJUKAN}

Anonim.2007. Petunjuk Praktikum Metabolisme Tumbuhan, FMIPA Biologi, Bogor: IPB.

Agne ,S Gigon. 2004. Effect of Drought Stress on Lipid Metabolism in the Leaves of Arabidopsis thaliana (Ecotype Columbia)

Ayhan Celik, 2000. Catalyticoxidation of p-Cresl by Ascorbate feroksidase. Archive of Biochemistry and Biophysics 373 :175-181

Chang .Je $-\mathrm{Hu}$.1968. Climate and Agriculture .An Ecological Survey. Aldine Publishing Company.

Darmijati .S.1992. Pengaruh Naungan Terhadap Pertumbuhan Kedelai dan Kacang Tanah. Journal Agroment VIII 1.32-40.

Dwijoseputro. 1990. Pengantar Fisiologi Tumbuhan Jakarta: Penerbit Gramadia.

Edmond J B. Senn A M . Andrews F A. 1983. Fundamental of Holticulture. New Delhi . Mc Graw Hill.

Ensiklopedia Pangan Plus. 2007. Pengaruh Pengolahan terhadap Biovalabilitas zat Besi Pangan. pluss All Right Reserved.

Salisbury, F.B. Clean W Ross .1991 Fisiologi Tumbuhan. Bandung: ITB.

Hughes .R. 1965. Climatic factors in relation to growth and survival of pasture Plants. J .Britt .grassal. Soc. 20:263-272.

Jones H G 1992 . Plants and Microclimate . Cambridge Univ Pr . 411p.

Lambers. H. Stuart, F.C. Thijs. 1998. Plant Physiological Ecology. Springer
Leegood. C.Peter J.Lea. 2001. Plant Biochemistry And Molecular Biology.Second edition. John Wiley and Sons

Sitompul, S.M. dan B.Guritno. 1995. Analisis Pertumbuhan Tanaman. Yogyakarta: Gajah Mada University Press.

Sumarni. 1996. Teknologi Bertanam Cabe. Yogyakarta: Gajah Mada Univercity Press.

Treshow. K.M. 1970. Environment and Plant Response. Mc Graw Hill Book Company 422 pp. 